\title{
Batch Drying in Sintering
}

\author{
B. A. Bokovikov ${ }^{a}$, V. I. Klein ${ }^{a}$, V. M. Malkin ${ }^{a}$, A. Yu. Petryshev ${ }^{b}$ and Yu. G. Yaroshenko ${ }^{b}$ \\ ${ }^{a}$ OOO NPVP TOREKS, Yekaterinburg, Russia \\ ${ }^{b}$ Yeltsin Ural Federal University, Yekaterinburg, Russia
}

\begin{abstract}
An adapted mathematical model of sintering permits analysis of the thermophysical characteristics of batch drying, primarily in the main sintering period. Over the whole length of the sintering machine, most of the bed volume corresponds to equilibrium moisture content, which may be higher or lower than the initial value. The temperature of the gas entering the drying zone is calculated, and its dependence on the parameters of the batch and gas is determined.
\end{abstract}

DOI: $10.3103 / \mathrm{S} 0967091213020046$

One of the most important components of iron-ore sintering is the drying of the batch [1-3]. Korotich made a major contribution to the study of sintering and, in particular, batch drying. As a rule, however, his analysis was based on the thermal and material balances, without regard for other processes and their interrelationships. His focus was on the initial period of drying. He noted the determining role of the hightemperature zone within the batch bed only in [3, p. 49]. In our view, the determining role of a particular zone must be determined not in the steady state but with variation in one of the input parameters of the batch or gas such that the zone boundaries in the bed are rearranged.

Very complex conditions prevail in the heat transfer between the gas and batch in the sintering bed and also with the hot fuel particles in the combustion zone (especially if they are large). In thermophysical terms, this complexity may be attributed to the presence of several powerful heat sources and sinks, which are comparable in magnitude: notably the combustion of fuel carbon with a thermal effect of about $+750 \mathrm{~kJ} / \mathrm{kg}$ of dry batch ( $\mathrm{kg} \mathrm{DB})$; the evaporation of moisture (about $-200 \mathrm{~kJ} / \mathrm{kg} \mathrm{DB}$ ), and batch melting and solidification (about $+300 \mathrm{~kJ} / \mathrm{kg} \mathrm{DB}$ ). Since the action of these heat sources (sinks) determines the formation of individual zones in the sintering bed and their mutual influence, all these phenomena must be considered together in the analysis of sintering.

Physical experiments on sintering machines and balance calculation can only reveal individual aspects of the complex drying conditions. The thermophysical principles and relations between individual phenomena may only be established by means of mathematical model providing a satisfactory description of the heat and mass transfer in the sintering bed, with allowance for the kinetics of all the basic physical and chemical processes. For the drying zone, such a model was developed (under certain assumptions) in [4], on the basis of the Reynolds model in [5]. We now present the basic equations of this model including the coefficients of heat and mass transfer (in our notation).

The drying rate is

$$
-\rho_{\mathrm{b}}(1-E) \partial U / \partial \tau=F \beta f(x),
$$

the variation in moisture content of the gas is

$$
E G_{\mathrm{d} . \mathrm{g}} \partial x / \partial h=F \beta f(x),
$$

and the equation for batch heating and drying is

$$
\begin{gathered}
\rho_{\mathrm{b}}(1-E) C_{\mathrm{b}} \partial t / \partial \tau \\
=\alpha F C_{\mathrm{g}}(T-t) /(1-x)-r F \beta f(x) .
\end{gathered}
$$

Here $\rho_{\mathrm{b}}$ is the apparent density of the batch, $\mathrm{kg} / \mathrm{m}^{3}$; $E$ is the bed porosity, expressed as a fraction; $\tau$ is the time, $\mathrm{s} ; U$ is the batch's moisture content, $\mathrm{kg} / \mathrm{kg} \mathrm{DB}$; $F$ is the batch's specific surface, $\mathrm{m}^{2} / \mathrm{m}^{3} ; \beta$ is the masstransfer coefficient, $\mathrm{kg} /\left(\mathrm{m}^{2} \mathrm{~s}\right) ; G_{\mathrm{d} . \mathrm{g}}$ is the consumption of dry gas, $\mathrm{kg} /\left(\mathrm{m}^{2} \mathrm{~s}\right) ; h$ is the bed height, $\mathrm{m} ; C_{\mathrm{b}}$ is the specific heat of the wet batch, $\mathrm{kJ} /(\mathrm{kg} \mathrm{K})$; $t$ is the temperature of the batch, $\mathrm{K}\left(\right.$ or $\left.{ }^{\circ} \mathrm{C}\right) ; T$ is the gas temperature, $\mathrm{K}$ (or $\left.{ }^{\circ} \mathrm{C}\right) ; \alpha$ is the heat-transfer coefficient, $\mathrm{kg} /\left(\mathrm{m}^{2} \mathrm{~s}\right)$; $C_{\mathrm{g}}$ is the specific heat of the wet gas, $\mathrm{kJ} /(\mathrm{kg} \mathrm{K}) ; r$ is the heat of vaporization of water, $\mathrm{kJ} / \mathrm{kg} ; f(x)=\left(x_{\mathrm{sat}}-x\right) /(1+x)$; $x$ is the moisture content of the gas, $\mathrm{kg} / \mathrm{kg}$.

This model of drying is fundamental to the sintering process at OOO NPVP TOREKS and to the dynamic model in [6]. Its capabilities were demonstrated in studying the influence of the initial batch temperature on the initial drying period [7].

In the Shklyar model, the heat- and mass-transfer coefficients are expressed as a function of the gas's moisture content, as in [5]. No account is taken of the change in the batch's specific surface during the condensation of water from the gas due to partial destruction of the saturated batch granules and the formation of water films on their surface or partial overlap of the pores in the bed. In addition, the evaporation process is regarded as analogous to evaporation from a free 


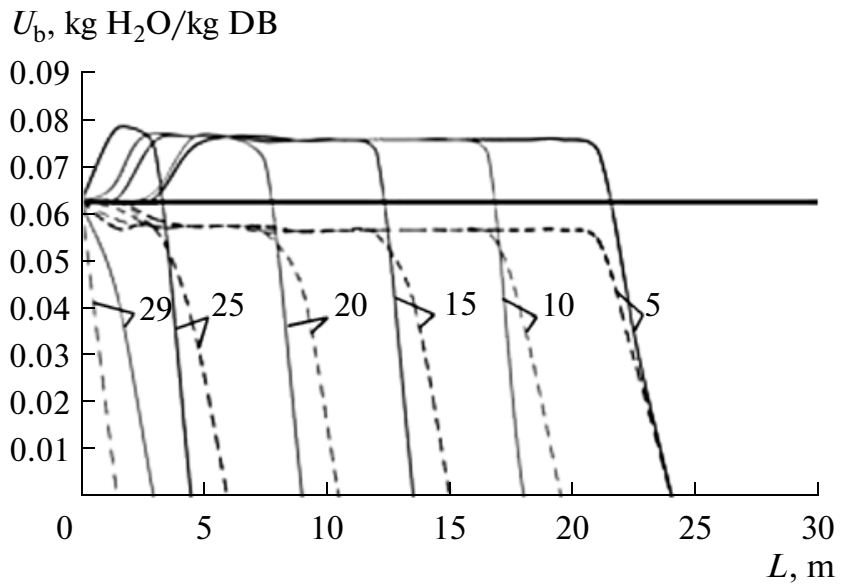

Fig. 1. Variation in batch moisture content $\left(U_{\mathrm{b}}\right)$ over the length $(L)$ of the sintering machine at different heights $(h)$ within the bed, when the initial batch temperature $t_{\mathrm{b}}^{\text {in }}=$ $25^{\circ} \mathrm{C}$ (continuous curves) and $65^{\circ} \mathrm{C}$ (dashed curves); the $h$ values $(\mathrm{cm})$ are given on the curves.

water surface, rather than from the pores of the batch. Nevertheless, the Shklyar model provides a good approximation to the real process overall, but it needs adaptation on the basis of reliable experimental data.

Since there are no large temperature gradients over time in the drying zone of the sintering bed (in contrast to the fuel-combustion zone), the temperature difference between the gas and the batch is slight. Accordingly, experimental thermograms may provide a reliable basis for the adaptation of the mathematical model. Verification shows that the theoretical heatand mass-transfer coefficients require significant correction. Account must be taken of the difference in these coefficients in the dry and wet batch. For that reason, the quantitative results of our calculations differ somewhat from those in [7].

The model is adapted on the basis of experimental data analogous to those in [8, p. 94]. In the present work, we present the most significant results of calculations based on that model. The goal of the research is to establish the fundamental thermophysical laws of batch drying, primarily in the main sintering period. Therefore, the gas-dynamic phenomena associated with variation of particular sintering parameters are disregarded. Although our focus is on the drying and rewetting of the batch, each calculation is conducted for the whole machine in the period up to the end of sintering. In the method, the productivity (speed of the batch cars) is selected, with any input parameters, so that the upper boundary of the combustion zone in the end of the machine is some distance from the bed boundary (the base or grating), which corresponds to normal sintering. Thus, with variation in any input parameter, the time is taken into account, although the batch parameters (moisture content, temperature) are plotted as a function of the length of the sintering machine.

For analysis of the basic case, we use the results of scale tests conducted in 2008 at the AKM-90 sintering machine (Abagursk sintering plant). In the calculations, the batch and gas parameters at the input to the bed varied widely, with constant filtration rate over the length of the machine. The gas temperature in the hearth (length $6 \mathrm{~m}$ ) was assumed to be $500^{\circ} \mathrm{C}$ over the first meter and then $1000^{\circ} \mathrm{C}$.

We now consider the general laws of drying in the sintering bed. As we know, the initial batch temperature $t_{\mathrm{b}}^{\text {in }}$ significantly affects the drying process in the bed. In Fig. 1, we show simulation results for drying at $t_{\mathrm{b}}^{\text {in }}=25$ and $65^{\circ} \mathrm{C}$, other conditions being equal (initial batch moisture content $6.4 \%$, recalculated for dry mass; filtration rate $0.25 \mathrm{~m} / \mathrm{s})$. Specifically, we show the time distribution of the batch moisture content at several heights in the bed (measured from the grating).

Under the given conditions, when $t_{\mathrm{b}}^{\text {in }}=25^{\circ} \mathrm{C}$, at all levels of the bed, rewetting of the bed begins, on account of condensation of moisture from vapor above the bed, and then an equilibrium state is established. The equilibrium moisture content at which the temperature is the same in the gas and the batch during the basic sintering period is a little less than the maximum rewetting and is practically unchanged until the basic drying period begins. When $t_{\mathrm{b}}^{\mathrm{in}}=45-50^{\circ} \mathrm{C}$, the rewetting at first may considerably exceed the equilibrium batch moisture content (as in the calculations of [7]). Subsequently, there is a period in which the batch dries to the equilibrium moisture content on account of the gas potential. When $t_{\mathrm{b}}^{\text {in }}=65^{\circ} \mathrm{C}$, there is practically no rewetting, and the equilibrium batch moisture content is below its initial value. In other words, at high batch temperatures, the equilibrium moisture content is established after primary drying.

Analysis of Fig. 1 indicates that the drying process

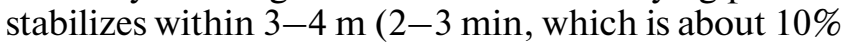
of the total length of the process) and is largely independent of $t_{\mathrm{b}}^{\text {in }}$. At different $t_{\mathrm{b}}^{\text {in }}$ values, the drying rate (slope of the curves) is considerably different at the beginning of the process but the same at the end of the process. In other words, the mean drying rate over the length of the machine is practically independent of $t_{\mathrm{b}}^{\text {in }}$. The data in Fig. 1 are in qualitative agreement with the results in [7, Fig. 4b].

Accordingly, separate zones form in the initial period of the press, depending on the initial batch temperature, as illustrated in Fig. 2 for the same conditions as in Fig. 1. It follows from Fig. 2a (where bed shrinkage is ignored, for the sake of clarity) that the average condensation time over the bed height is $1.5 / 30=0.05$ ( or $5 \%$ ) of the total duration of the pro- 
cess. The absolute condensation time over most of the bed height is $1.5 / 1.585$ or about $1 \mathrm{~min}$, where 1.585 is the speed of the batch car $(\mathrm{m} / \mathrm{min})$. In the given conditions, the zones of carbon combustion and drying in the basic sintering period are practically the same: $17.3 \mathrm{~mm} / \mathrm{min}$, on average. The condensation zone moves at $\sim 90 \mathrm{~mm} / \mathrm{min}$, which is 5.2 times higher. (Similar data were given in [7].) The sintering rate (the speed at which the lower boundary of the combustion zone moves over the bed height) at the hearth (over a length of $6 \mathrm{~m}$ ) and in the remainder of the machine is practically the same as the speed of the drying zone's lower boundary. With increase in $t_{\mathrm{b}}^{\text {in }}$ to $65^{\circ} \mathrm{C}$ (Fig. 2b), the mean (over the length of the machine) speed of the combustion and drying zones is slightly increased (to $17.9 \mathrm{~mm} / \mathrm{min}$, or by $3.5 \%$ ). The height of the drying zone is reduced by $25-30 \%$ on average (approximately in proportion to the equilibrium batch moisture content), while the primary-drying zone moves over the height at a speed ten times greater than the combustion and drying rates. The primary-drying time is $0.6 \mathrm{~min}$ in the upper part of the bed and $1.6 \mathrm{~min}$ in the lower part, for the given conditions.

Thus, it follows from Fig. 2 that the initial batch temperature not only affects the drying process in the initial period but radically changes the drying process in the bed over the whole machine. With increase in $t_{\mathrm{b}}^{\text {in }}$ from 25 to $65^{\circ} \mathrm{C}$, the rewetting zone gradually disappears and is replaced by a primary-drying zone of similar size that moves twice as fast over the bed height. Thus, the rewetting zone traditionally identified for a specific batch only exists in certain conditions-at low $t_{\mathrm{b}}^{\text {in }}$. At high $t_{\mathrm{b}}^{\text {in }}$, the equilibrium batch moisture content is below the initial moisture content.

Many parameters of the batch and the gas flux affect the formation of zones in the sintering bed. However, there is little material on this topic in the literature. Usually, only two zones are considered: carbon combustion; and drying of the batch. As already noted, Korotich believed that, of these two zones, "the high-temperature zone is determining ... The drying zone is adapted to the high-temperature zone so that the gas flow rates in the two zones are the same" [3]. As proof, Korotich offered an example in which the drying zone approached the combustion zone with increase in the batch moisture content. In this example, "the temperature of the gas entering the primarydrying zone increases, while the process is adapted to the increased batch moisture content at the previous gas flow rate." The latter is only partially confirmed by simulation: the temperature of the gas entering the drying zone in fact increases (by $25-30^{\circ} \mathrm{C}$ per $1 \%$ batch moisture content). At the same time, the sintering rate slightly declines (by $2 \%$ per $1 \%$ batch moisture content), and the speed of the batch car falls. In other words, the drying period increases. Correspondingly, the temperature of the gases leaving the combustion

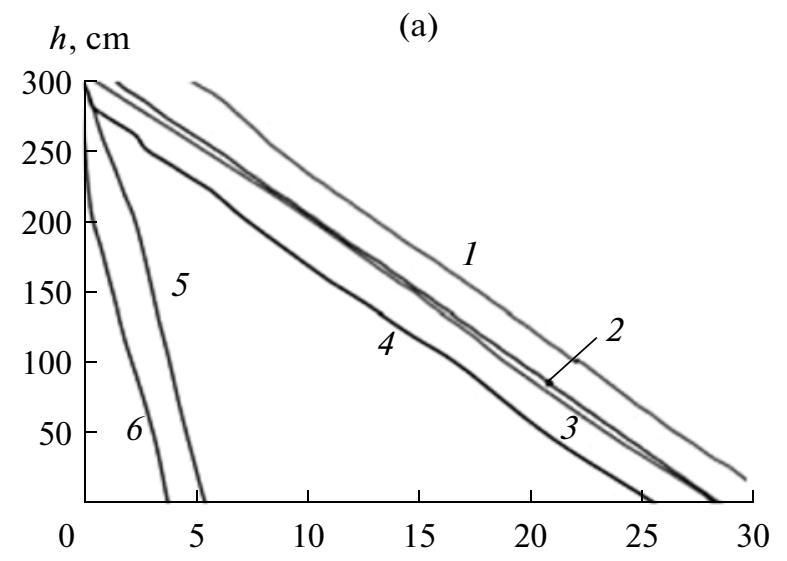

(b)

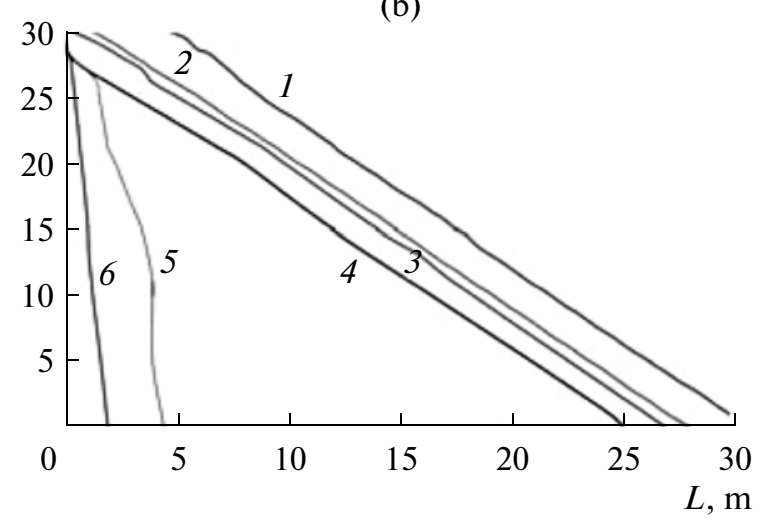

Fig. 2. Boundaries of the basic zones in the sintering bed when the initial batch temperature $t_{\mathrm{b}}^{\text {in }}=25^{\circ} \mathrm{C}$ (a) and $65^{\circ} \mathrm{C}$ (b): (1) fuel-combustion zone; (2) heating zone; (3) drying zone; (4) equilibrium batch moisture content; (5) condensation zone; (6) initial batch.

zone increases. Hence, in that case, the process is not completely adapted to the increased batch moisture content. Korotich's conclusions are based on balance calculations and experimental thermograms obtained in a sintering pan. Therefore, they are approximate, and the formation of individual zones within the sintering bed remains an open question. In our view, it cannot be resolved by balance calculations and temperature measurements in the bed.

Sintering is a typical two-dimensional heat- and mass-transfer process. In the initial stage (fuel ignition and external heating of the bed), zones corresponding to individual thermal and physical processes are formed. Then, in the absence of external perturbations, these zones move downward through the bed, at constant speed. The sharp decrease in air temperature as it enters the bed after escaping from under the hearth hardly changes the speeds of the sintering and drying zones on account of their depth in the bed at that time. Of course, the formation of the zones in the initial stage depends on the kinetics of all the processes; none of the zones may be determining in all conditions. As an illustration, consider how the for- 


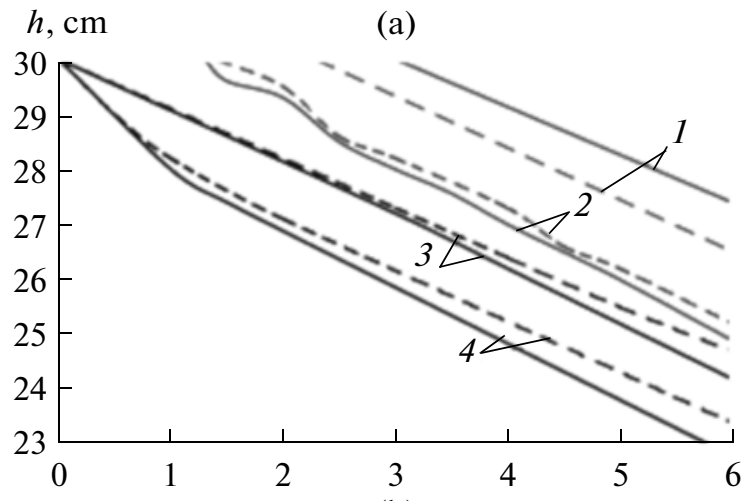

(b)

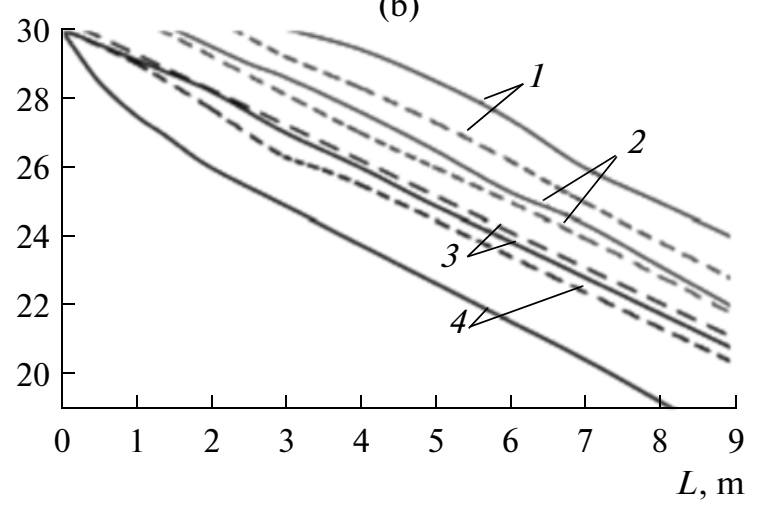

Fig. 3. Zone formation in the sintering bed: (a) when the filtration rate is $0.2 \mathrm{~m} / \mathrm{s}$ (continuous curves) and $0.3 \mathrm{~m} / \mathrm{s}$ (dashed curves); (b) when the diameter $d_{\mathrm{b}}$ of the batch particles is $1.5 \mathrm{~mm}$ (continuous curves) and $5.5 \mathrm{~mm}$ (dashed curves); $(1,2)$ upper and lower boundaries of the combustion zone; $(3,4)$ upper and lower boundaries of the drying zone.

mation of the combustion and drying zones depends on factors such as the filtration rate and the specific surface of the batch in the bed $\left(\mathrm{m}^{2} / \mathrm{m}^{3}\right)$. In Fig. 3a, we show simulation results for the formation of zones at constant filtration rates of 0.20 and $0.30 \mathrm{~m} / \mathrm{s}$ over the length of the machine, when the other conditions are constant: batch moisture content $6.4 \mathrm{~kg} / \mathrm{kg} \mathrm{DB}$; mean size of batch particles $2.5 \mathrm{~mm}$; carbon content in batch $3.4 \mathrm{~kg} / \mathrm{kg} \mathrm{DB}$; and mean size of fuel particles $1.7 \mathrm{~mm}$.

As follows from Fig. 3a, sintering may be divided over the length of the machine into two fundamentally different sections: (1) transient conditions in the formation of the zones, which end long before the batch bed emerges from the hearth (the initial sintering period $[3,7])$; (2) relatively stable positions of the combustion and drying zones and constant sintering rate over the height of the bed and the length of the machine (the section with steady conditions).

Analysis of the results also indicates that, with increase in the filtration rate $W_{\mathrm{f}}$ from 0.2 to $0.3 \mathrm{~m} / \mathrm{s}$, the configuration of the drying and heating zones is practically unchanged, although they move at greater speed over the bed height. That may be explained in that the strong external perturbation (the increase in $\left.W_{\mathrm{f}}\right)$ is compensated by practically proportional increase in the sintering rate: with 1.5 -fold increase in $W_{\mathrm{f}}$, the sintering rate $U_{\mathrm{si}}$ increases from 13.2 to $21.7 \mathrm{~mm} / \mathrm{min}$ (by a factor of 1.65). With increase in $W_{\mathrm{f}}$, the position of the combustion zone's lower boundary over the length of the machine is almost unchanged, while the height of the combustion zone is almost halved as a result of more intense carbon combustion. The speed of the drying zone over the bed height in both cases is about the same as the sintering rate. For those conditions, we may conclude that the combustion zone plays the dominant role. The heating zone between the combustion and drying zones remains practically unchanged; its height is no more than $10 \mathrm{~mm}$. Note that the sintering rate here is regarded as the speed of the lower boundary of the fuel-combustion zone over the bed height.

The formation of the zones is completely different with different specific surface of the batch (for different particle size). In Fig. 3b, we show the combustion, heating, and drying zones for small and large batch particles. As we see, when the batch's specific surface is large $\left(d_{\mathrm{b}}=1.5 \mathrm{~mm}\right)$, the drying zone is formed over a length of $1.5-2.0 \mathrm{~m}(\sim 1 \mathrm{~min})$ and a height of $\sim 8 \mathrm{~mm}$ and moves downward through the bed at constant speed. The heating zone (between the combustion and drying zones) is comparable in size with the drying zone and ensures that the temperature of the gas entering the drying zone is $190^{\circ} \mathrm{C}$.

With increase in particle diameter to $d_{\mathrm{b}}=$ $5.5 \mathrm{~mm}$ - that is, with decrease in the batch's specific surface by a factor of 3.7 - the formation of the zones is very different. On account of the reduced temperature gradient of the gas over the bed height and correspondingly the reduced heat-transfer rate, batch drying penetrates to about twice the depth before fuel ignition, while the height of the drying zone is almost tripled (practically in proportion to the decrease in the batch's specific surface). The upper boundary of the drying zone moves at almost constant speed over the bed height. The height of the heating zone is also approximately doubled, while the temperature of the gas entering the drying zone is increased to $300^{\circ} \mathrm{C}$. The combustion zone is somewhat delayed (relative to the drying zone) and also expanded, but only by a factor of 1.5 (other conditions being equal). Therefore, we may regard the drying zone as the dominant factor. That example indicates that the relation between the individual zone and the role of the kinetics of the individual processes in zone formation do not correspond to the conventional theoretical assumptions.

Thus, simulation shows that the formation of zones in the sintering bed is determined by the kinetics of all the processes associated with sintering, and modification of any parameter of the batch or gas will produce different restructuring of the zones. 
We now consider some thermophysical aspects of the steady state identified in simulating the influence of various batch and gas parameters on the sintering process. (The calculation method is as before, with the selection of the batch-car speed that corresponds to the end of bed sintering precisely at the end of the machine and with constant filtration rate over the length of the machine.) One of the most important and least studied parameters of the drying in the sintering bed is the temperature of the gas entering the drying zone. "Experimental measurement of the temperature of the gas entering the drying zone is impossible," according to [3, p. 40]. Thermal-balance calculations for the drying zone show that $T_{\mathrm{d}}^{\text {in }}=300-$ $400^{\circ} \mathrm{C}$ in ordinary sintering conditions.

In contrast to roasting machines for oxidized-pellet production, where the gas temperature in the drying zones is specified in the range $250-400^{\circ} \mathrm{C}$ in accordance with the properties of the unroasted pellets (in other words, where the gas temperature is an independent variable), the temperature of the gas entering the drying zone $\left(T_{\mathrm{d}}^{\mathrm{in}}\right)$ in sintering is a function of many batch and gas parameters. In simulation, to determine $T_{\mathrm{d}}^{\mathrm{in}}$, the dependence of the gas temperature on the batch moisture content $\left(U_{\mathrm{b}}\right)$ is plotted from the calculated variable fields. This dependence is practically linear and may be extrapolated to the point $\left(U_{\mathrm{b}}=0\right)$ (to the beginning of drying). The results of extrapolation are shown in Fig. 4 as plots of $T_{\mathrm{d}}^{\text {in }}$ against the main sintering parameters.

It follows from Fig. 4a that the filtration rate has little effect on the temperature of the gas entering the drying zone (the change is $15^{\circ} \mathrm{C}$ per $0.10 \mathrm{~m} / \mathrm{s}$ ), whereas increasing the initial batch temperature from 25 to $65^{\circ} \mathrm{C}$ reduces $T_{\mathrm{d}}^{\mathrm{in}}$ by about $50^{\circ} \mathrm{C}$. Considerable increase in batch moisture content from 6.4 to $8.7 \%$ (for dry batch) increases $T_{\mathrm{d}}^{\text {in }}$ by the same amount (Fig. 4b). The increase in $T_{\mathrm{d}}^{\mathrm{in}}$ is especially great with increase in diameter of the batch particles - that is, with decrease in specific surface of the batch. For the given range of specific surface (from 2600 to $975 \mathrm{~m}^{2} / \mathrm{m}^{3}$ ), $T_{\mathrm{d}}^{\text {in }}$ changes by $80^{\circ} \mathrm{C}$ (Fig. $4 \mathrm{~b}$ ). Since $T_{\mathrm{d}}^{\text {in }}$ is the drying potential, the evaporation rate of the moisture is practically proportional to $T_{\mathrm{d}}^{\mathrm{in}}$. As follows from Fig. 4, the temperature of the gas entering the drying zone is $200-300^{\circ} \mathrm{C}$, and a change of $50-80^{\circ} \mathrm{C}$ must be regarded as very significant. The fluctuations in $T_{\mathrm{d}}^{\mathrm{in}}$ are associated with change in the heat-transfer conditions within the batch.

Of course, $T_{\mathrm{d}}^{\mathrm{in}}$ is also affects the heat-transfer conditions in the lower levels of the bed, with correspond-

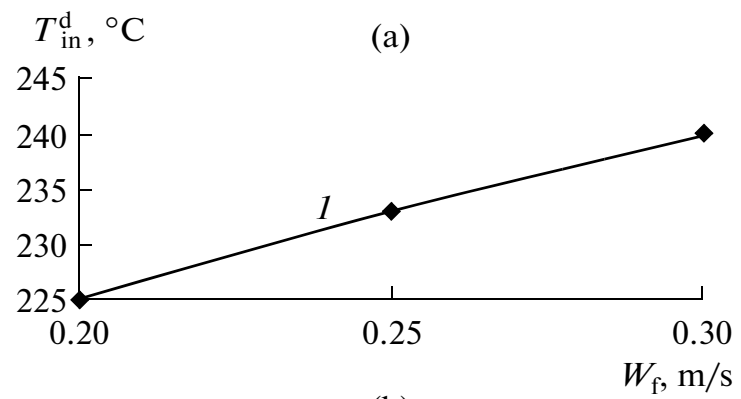

(b)

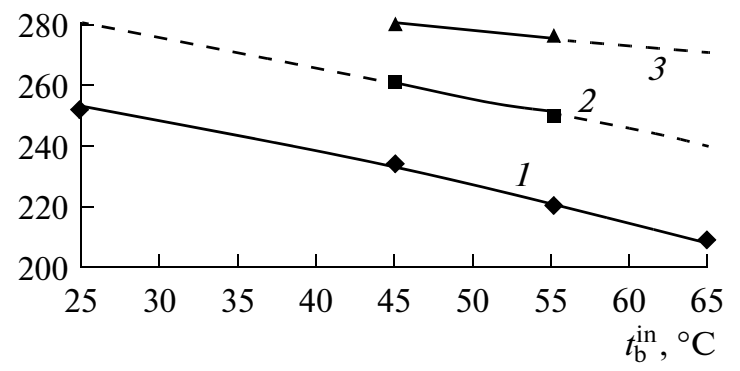

(c)

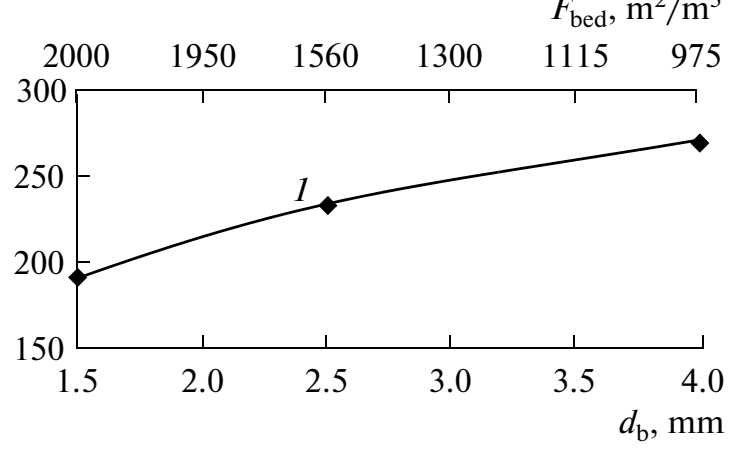

Fig. 4. Temperature of the gas entering the drying zone $\left(T_{\mathrm{d}}^{\mathrm{in}}\right)$ as a function of the filtration rate (a), the initial batch temperature (b), and the diameter of the batch particles $d_{\mathrm{b}}$ and the bed's specific surface $F_{\mathrm{bed}}(\mathrm{c})$, when the initial batch moisture content $\left(U_{\mathrm{b}}^{\mathrm{in}}\right)$ is $6.4 \%(1), 7.5 \%$ (2), and $8.7 \%$ (3) with respect to the dry mass.

ing change in the equilibrium temperature and moisture content of the batch. Calculations of the equilibrium temperature on the basis of the thermal balance in drying must be regarded as qualitative [3, pp. 39-40]. Data regarding the equilibrium temperature at the beginning of sintering were presented in [7]. The equilibrium temperature at the beginning of sintering was also discussed in [9, Sec. 3.2]. Our model calculations permit estimation of the equilibrium conditions in the batch bed during the basic sintering period (according to Korotich's terminology), as a function of the main sintering parameters.

In Fig. 5a, we plot the equilibrium temperature in the batch bed as a function of the temperature of the gas entering the drying zone. That dependence is practically linear with relatively broad variation in the 

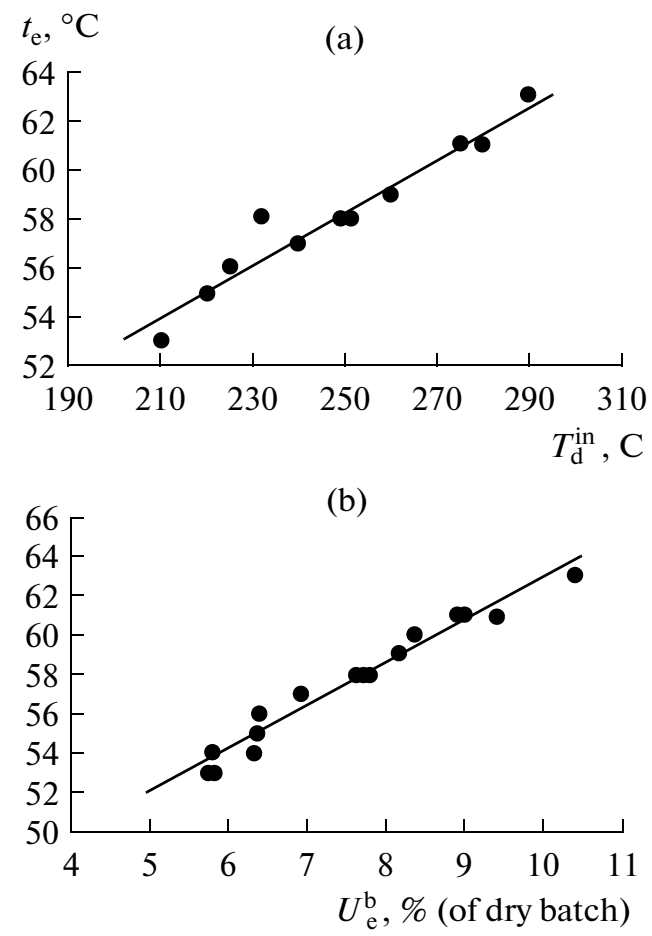

Fig. 5. Dependence of the equilibrium temperature $t_{\mathrm{e}}$ on the temperature of the gas entering the drying zone $T_{\mathrm{d}}^{\text {in }}$ (a) and on the equilibrium batch moisture content $U_{\mathrm{e}}^{\mathrm{b}}(\mathrm{b})$, when $W_{\mathrm{f}}=0.2-0.3 \mathrm{~m} / \mathrm{s} ; U_{\mathrm{b}}=6.4-8.7 \%$; and $t_{\mathrm{b}}^{\text {in }}=25-$ $65^{\circ} \mathrm{C}$.

batch and gas parameters. According to these data, the equilibrium temperature is $5-10^{\circ} \mathrm{C}$ higher than in the balance calculations. In Fig. 5b, we show the relation between the equilibrium temperature and batch moisture content in the bed after rewetting or drying. This relation is also linear with relatively broad variation in the batch and gas parameters, obviously on account of the onset of thermal equilibrium between the batch and gas flux.

The initial values of the batch temperature and moisture content have relatively little influence on the sintering productivity in conditions of heat and mass transfer (with constant filtration rate or, in other words, when disregarding the gas dynamics). With increase in the batch moisture content from 6 to $8 \%$ (for wet mass), the belt mass must be reduced by no more than $4 \%$. Increasing the batch temperature only affects the belt speed when the batch moisture content is $8 \%$, and the change in speed is slight $(2 \%)$. However, these batch parameters have great influence on the drying conditions: the equilibrium values of the batch temperature and batch moisture content.

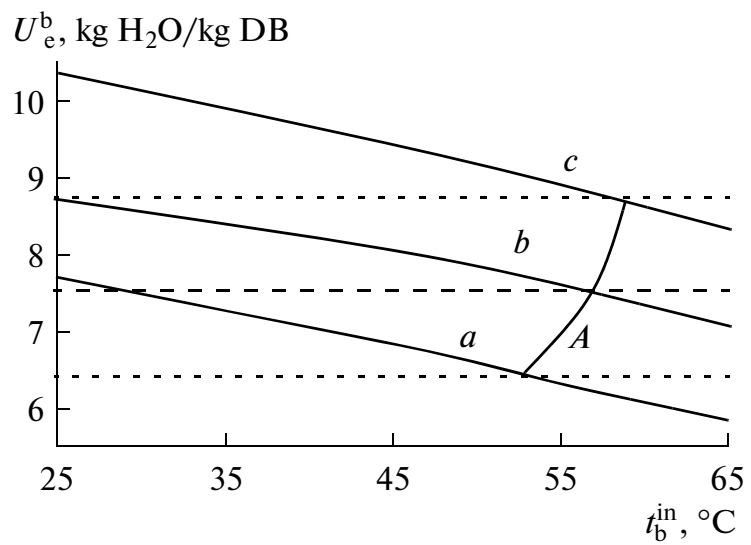

Fig. 6. Dependence of the equilibrium batch moisture content $U_{\mathrm{e}}^{\mathrm{b}}$ on the initial batch temperature and moisture content. On curve $A, U_{\mathrm{e}}^{\mathrm{b}}=U_{\mathrm{b}}^{\mathrm{in}}$ : (a) $6.4 \mathrm{~kg} \mathrm{H}_{2} \mathrm{O} / \mathrm{kg} \mathrm{DB}$; (b) $7.5 \mathrm{~kg} \mathrm{H} \mathrm{H}_{2} \mathrm{O} / \mathrm{kg} \mathrm{DB}$; (c) $8.7 \mathrm{~kg} \mathrm{H}_{2} \mathrm{O} / \mathrm{kg} \mathrm{DB}$.

In Fig. 6, we show the equilibrium batch moisture content as a function of the initial batch temperature and moisture content; this dependence is obtained by analysis of the simulation results for the basic sintering period. It follows from Fig. 6 that, when $t_{\mathrm{b}}^{\text {in }}<53-59^{\circ} \mathrm{C}$ (depending on the initial batch moisture content), the equilibrium moisture content exceeds the initial value. In other words, we observe rewetting of the batch.

For the assumed porosity of the batch particles (25\%), the maximum capillary moisture content is $8.7 \%$ (for dry mass). Hence, when $U_{\mathrm{b}}^{\mathrm{in}}=8.7 \%$ (dry) and $t_{\mathrm{b}}^{\mathrm{in}}<57-58 \%$, condensation inevitably leads to the formation of free moisture in the bed. With lower initial moisture content, the pores and surface of the bath particles absorb practically all the condensate.

\section{CONCLUSIONS}

(1) Our results show that the thermophysical characteristics of batch drying and sintering may be identified more precisely (with allowance for the kinetics of all the basic processes) on the basis of appropriately adapted mathematical models.

(2) Simulation shows that, throughout the sintering process, most of the bed is occupied by batch with equilibrium moisture content, which may be higher or lower than the initial value, depending on the initial batch temperature. The equilibrium moisture content depends linearly on the temperature of the gas entering the drying zone (analogously to the equilibrium temperature) and depends weakly on the filtration rate. The dependence of the equilibrium moisture 
content on the initial batch temperature and moisture content is established.

(3) With increase in $t_{\mathrm{b}}^{\text {in }}$ from 25 to $65^{\circ} \mathrm{C}$, the rewetting zone gradually disappears and is replaced by a primary-drying zone. The rewetting zone traditionally only exists at low initial batch temperature $t_{\mathrm{b}}^{\text {in }}$. At high $t_{\mathrm{b}}^{\text {in }}$, the equilibrium batch moisture content is below the initial moisture content.

(4) As shown by the simulation, the temperature of the gas entering the drying zone is $200-300^{\circ} \mathrm{C}$ (about $100^{\circ} \mathrm{C}$ less than the literature values), with relatively broad variation in the batch and gas parameters. This temperature is shown to depend on the filtration rate, the initial batch temperature, and the batch moisture content and particle size.

(5) Simulation permits analysis of the formation of the individual zones within the sintering bed in different conditions. Thus, with variation in the filtration rate or particle size, the formation of these zones will be different. The fuel-combustion and drying zones may be regarded as critical.

(6) Further study of the thermophysical characteristics of batch drying is required in view of the multiplicity of relevant factors (with particular attention to the batch composition and properties).

\section{REFERENCES}

1. Korotich, V.I. and Puzanov, V.P., Formation of Rewetting Zones in Sintering by the Suction Method,
Izv. Vyssh. Uchebn. Zaved., Chern. Metall., 1964, no. 10, pp. 28-33.

2. Korotich, V.I., Puzanov, V.P., and Frolov, Yu.A., Behavior of Moisture and Gas Dynamics of the Sintering Bed in the Initial Period, Izv. Vyssh. Uchebn. Zaved., Chern. Metall., 1968, no. 10, pp. 26-30; no. 12, pp. 37-41.

3. Korotich, V.I., Frolov, Yu.A., and Kaplun, L.I., Teoreticheskie osnovy tekhnologii okuskovaniya metallurgicheskogo syr'ya. Aglomeratsiya: uchebnoe posobie (Theoretical Principles of Ore Pelletization: Sintering: A Textbook), Yekaterinburg: GOU VPO UGTU-UPI, 2005.

4. Raeva, M.V., Shklyar, F.R., and Frolov, Yu.A., Model of the Heat and Mass Transfer in Porous-Bed Drying, Metallurg. Teplotekhn., 1974, no. 2, pp. 154-162.

5. Spalding, D.B., Convective Mass Transfer: An Introduction, New York: McGraw-Hill, 1963.

6. Frolov, Yu.A., Polotskii, L.I., Kobelev, V.A., and Konoplyanik, V.V., Three-Dimensional Dynamic Model of Sintering, Byull. TsNIIChM, 2005, no. 11, pp. 29-30.

7. Frolov, Yu.A., Konoplyanik, V.V., Isaenko, G.E., et al., Analysis of Drying, Condensation, and Gas Dynamics in the Sintering Bed during the Initial Period, Stal', 2008, no. 6, pp. 5-13.

8. Korotich, V.I. and Puzanov, V.P., Gazodinamika aglomeratsionnogo protsessa (Gas Dynamics of Sintering), Moscow: Metallurgiya, 1969.

9. Klein, V.I., Maizel', G.M., Yaroshenko, Yu.G., and Avdeenko, A.A., Teplotekhnicheskie metody analiza aglomeratsionnogo protsessa (Thermal Methods of Sintering Analysis), Yekaterinburg: GOU VPO UGTUUPI, 2004.

Translated by B. Gilbert 